\title{
HYDROGEOLOGICAL ASSESSMENT OF GROUNDWATER DEGRADATION AT THE EASTERN NESTOS RIVER DELTA, N.E. GREECE.
}

\author{
Gkiougkis I. ${ }^{1}$, Mwila, G. ${ }^{2}$, Pliakas F. ${ }^{3}$, Kallioras A. ${ }^{4}$, and Diamantis I. ${ }^{5}$ \\ ${ }^{1}$ Democritus University of Thrace, Department of Civil Engineering, Laboratory of Engineering Geology, \\ 67100 Xanthi, Greece, jgiougis@civil.duth.gr \\ ${ }^{2}$ Technical University of Darmstadt, Institute of Applied Geosciences, Hydrogeology Group, 64287 Darm- \\ stadt,Germany,gbmwila@yahoo.com \\ ${ }^{3}$ Democritus University of Thrace, Department of Civil Engineering, Laboratory of Engineering Geology, \\ 67100 Xanthi, Greece, fpliakas@civil.duth.gr \\ ${ }^{4}$ Technical University of Darmstadt, Institute of Applied Geosciences, Hydrogeology Group, 64287 Darm- \\ stadt,Germany, kallioras@geo.tu-darmstadt.de \\ ${ }^{5}$ Democritus University of Thrace, Department of Civil Engineering, Laboratory of Engineering Geology, \\ 67100 Xanthi,Greece,jdiam@ civil.duth.gr
}

\begin{abstract}
This paper deals with the hydrogeological study of the evolution of groundwater salinisation - degradation at the eastern Nestos River Delta. Relevant field works including in-situ measurements of groundwater level, $p H$, Specific Electrical Conductivity (SEC) and temperature took place in the years 2008 and 2009. Groundwater samples were also collected for chemical analysis at the Engineering Geology Laboratory of the Department of Civil Engineering of D.U.Th. (July of 2009). Important conclusions regarding the progress of the groundwater degradation at the study area were drawn based on the analysis of all the available data and the elaboration of the designed piezometric maps and the various maps showing the distribution of SEC, Chloride, SAR (Sodium Absorption Ratio) and Revelle coefficient values. Some managerial suggestions for the confrontation of the seawater intrusion regime of the study area are also included.
\end{abstract}

Key words: coastal aquifers, seawater intrusion, groundwater quality, N.E. Greece.

\section{Introduction}

Seawater intrusion is a widespread environmental phenomenon which takes place in most coastal aquifers, especially those which are located within the Mediterranean coastal zone. This is mainly due to the climatological conditions, which are related to hot and dry summers, as well as due to the extensive farming and other anthropogenic activities occurring at the coastal zone. Greece is one of the most affected countries of the Mediterranean region, partially due to the fact that farming and agriculture is a core element of the national economy (hence large amounts of groundwater are being extracted every year) and on the other hand the long shoreline of the country does not enhance the application of countermeasure techniques (high financial costs). Once seawater has intruded the coastal aquifer and the pumping conditions continue to take place extensively, the hydraulic regime 


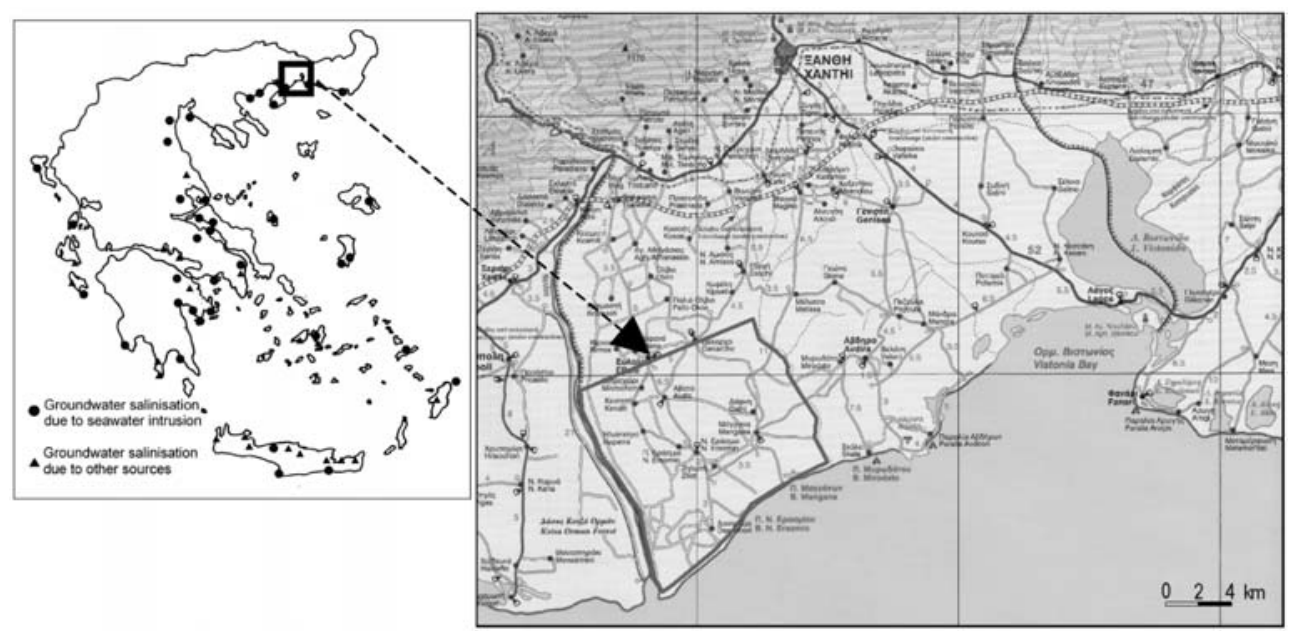

Fig. 1: Areas of groundwater salinization in Greece (modified map of the Ministry of Agriculture) and location of the study area (Gkiougkis, 2009; Kallioras, et al., 2006).

may be altered in such a manner so that it may produce active seawater intrusion. This is the case where the rehabilitation of the groundwater resources qualitative regime is rather not feasible (Gaaloul et al., 2008).

Seawater encroachment appears within the majority of the coastal aquifers in Greece, which are under hydrogeological investigation, and is responsible for their qualitative degradation (Fig. 1). Today, all scientific evidences lead to the conclusion that the encroachment of seawater into coastal aquifers is a phenomenon that regards the majority of the coastal area of northern Greece, including the coastal area of Eastern Macedonia and Thrace (Kallioras et al. 2006).

The construction of several drainage works and the increasing use of irrigation water in the east delta plain of the River Nestos, have resulted in seawater intrusion and related deterioration of the groundwater quality (Gkiougkis, 2009, Daskalopoulos, 2007, Sakkas et al., 1998, Pliakas et al., 2001). This paper deals with the study of hydrogeological and hydrochemical characteristics of the coastal aquifer system of the eastern delta area of the Nestos River, with the aim of contributing to the understanding of processes which lead to groundwater quality degradation due to over pumping of groundwater for irrigation from the unconfined coastal aquifer.

\section{Geomorphological and geological framework, hydrogeology}

The study area is located south of the city of Xanthi in the prefecture of Xanthi, N.E. Greece. It is bounded to the west by the Nestos River and to the south by the Aegean Sea (Fig. 1). The morphology of the region is characterised by a very low relief and shallow pits, to the $\mathrm{S}$ and SE, forming small ponds, which are part of the eastern Nestos delta wetlands. The geomorphology of the study area is characterised as being generally flat, with elevation of a few meters above sea level throughout the entire study site. The most important surface water body of the area is River Nestos located to the west of the study area. It is also the one of the main sources of freshwater recharge for the coastal unconfined aquifer, as it flows through the area from the north-northwest to the southsoutheast into the Thracean Sea. Laspias stream is located across the eastern side of the study area 
where the degraded industrial and sewage treatment effluents are discharged. Northerly, at a distance of approximately $2 \mathrm{~km}$, a drainage trench is located, which after draining the northerly irrigated land, conveys water into the Laspias stream.

The main agricultural activity is cultivation of corn and cotton which is done by irrigation with groundwater from the coastal aquifer. Main crops are maize (occupying more than $50 \%$ of the land under cultivation), cereals, trefoil, sugar beet, garden products, industrial tomato, cotton and tobacco. The intensive agricultural activities in combination with the irrational use of fertilizers and insecticides have resulted in severe problems such as soil degradation, exhaustion of the aquifers potential and increase of the salt concentrations in the shallow aquifers particularly in the coastal areas.

The study area is located in a recent sedimentary delta environment of a thickness of some tens of meters created by the Nestos deposits. These alternate sand, clay and silt layering deposits, resulting from a wide range of structural and depositional processes, produce a heterogeneous geological environment. It is worth mentioning the presence of organic clay at some points due to the delta marshes. The evolution of the east part of the delta under flooding conditions has been instrumental in forming low potential aquifers in the study area (Gkiougkis, 2009; Mwila, 2009).

There is a geological study which has included the necessary relative research works such as test drillings, piezometers and geophysical exploration and the study of the well geologic logs of the study area. It was concluded that at the north side of the study area, alternate clay and mostly sand layering extend down to the depth of $30 \mathrm{~m}$. A marly layer of $50 \mathrm{~m}$ thickness comes in between. Below the depth of $80 \mathrm{~m}$, the same clay and sand layers extend again (Pliakas, et al., 2001, Sakkas, et al., 1998).

The east delta plain extends to $176.4 \mathrm{~km}^{2}$, from which the $106.63 \mathrm{~km}^{2}$ are cultivated (only $60 \%$ ), while the coastal saline uncultivated lands extend to $45 \mathrm{~km}^{2}$. Considering the hydrological data of Nestos Delta plain (mean annual rainfall for the period 1965 - 1996: 546.9 mm, infiltration approximately: $15 \%)$, the annual infiltration for the $131.4 \mathrm{~km}^{2}$ area $(176.4-45=131.4)$ is estimated at $10.8 \times 10^{6} \mathrm{~m}^{3}$. The irrigated lands extend to $89,893 \mathrm{~km}^{2}$, while the $35 \mathrm{~km}^{2}$ of them meet irrigation needs from the Nestos River. The rest areas meet irrigation needs by pumping, where considering the type and the extent of the crops as also as well operation data, the annual water consumption is estimated at $27 \times 10^{6} \mathrm{~m}^{3}$. Taking into account the amounts of the two basic parameters of the groundwater hydrologic balance mentioned above (infiltration - water consumption), a lack of about $16 \times 10^{6}$ $\mathrm{m}^{3}$ water is evaluated (Pliakas, et al., 2001, Sakkas, et al., 1998). It is estimated that a small part of this lack is replaced by the Nestos riverbed percolation, at rates depending on the run of the buried old streambeds and the distance from the river (Gkiougkis, 2009; Mwila, 2009).

There are two hydrogeological systems that are formed within the alluvial deposits of the wider study area (Pliakas, et al., 2001, Sakkas, et al., 1998): (a) The shallow system, consisting of phreatic and mostly of semi-confined aquifers extended down to a depth of about $30 \mathrm{~m}$. Natural recharge to this system comes mostly from the infiltration of rainfall and less from stream bed percolation of the north hilly area. During the 90s, a great amount of small diameter (3") shallow wells (up to $20 \mathrm{~m}$ depth) were pumping water out of the system. Nowadays, only few of them are operated, whilst many of the other shallow wells have been replaced by deeper wells (up to $50 \mathrm{~m}$ depth), like in Dekarchon area. (b) The deeper system, consisting of confined aquifers extended to a depth of at least $190 \mathrm{~m}$. Natural recharge to this system comes to a great extent from river Nestos percolation through buried old stream beds, and from the lateral groundwater inflows coming from the adjoining Vistonis lagoon hydrogeological basin. There are about functional 50 deep wells (up to $320 \mathrm{~m}$ depth), located in the main study area. 


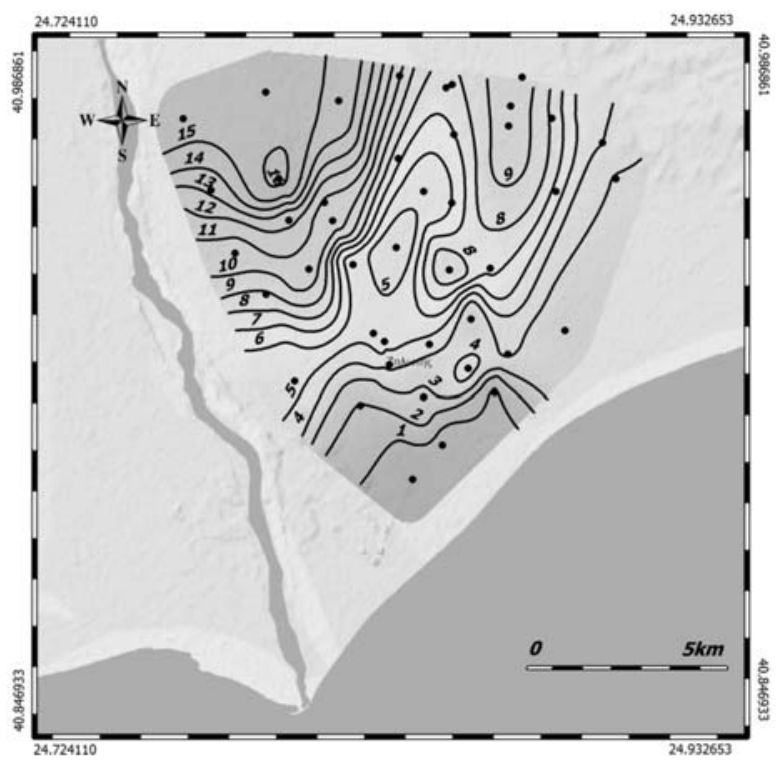

Fig. 2a: Piezometric map, October 2008 (Gkiougkis, 2009; Mwila, 2009).

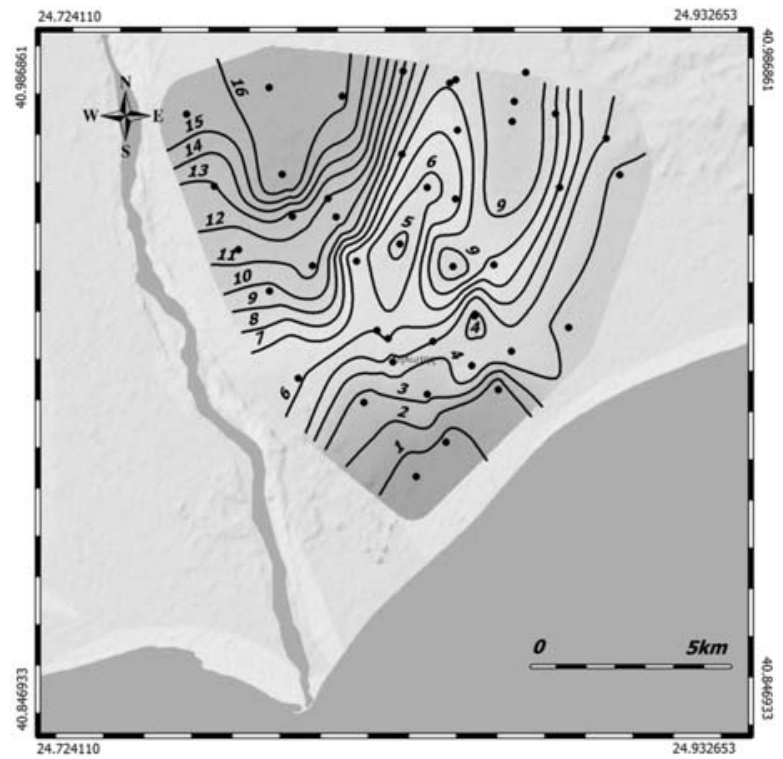

Fig. 2b: Piezometric map, April 2009 (Gkiougkis, 2009; Mwila, 2009).

Evaluation of the groundwater hydraulic parameters of the study area aquifers after working out the results from the pumping tests of 11 selected wells in the wider study area resulted in values for (Pliakas, et al., 2001, Sakkas, et al., 1998): (1) transmissivity (T), ranging from $4.0 \times 10^{-4}$ to $1.1 \times 10^{-2}$ $\mathrm{m}^{2} / \mathrm{sec}$, (2) storage coefficient (S), ranging from very low values to $10^{-3}$, characterizing the aquifers of the study area as confined mainly westward, and in some sites as semiconfined. 
Figure 2a shows the piezometric map of the study area as of October 2008 just after the irrigation period, while Fig. 2b shows the piezometric map for the same area in April 2009 before the irrigation period. Comparing the two maps it is worth noting that the major groundwater flow direction is from the northwest towards the south with minor flow from the N.E. and central parts of the study area towards the south.

\section{Groundwater quality}

The Laboratory of Engineering Geology of the Department of Civil Engineering, D.U.Th., Greece, in collaboration with the Hydrogeology Group of the Technical University of Darmstadt, Institute of Applied Geosciences, Germany, conducted a groundwater quality research at the study area during the summer of 2009. Groundwater samples were collected 30 selected wells for a period of two days, on 1/7/2009 and 2/7/2009. Sampling also included in situ measurements of the physicochemical parameters of the groundwater of the study area $(\mathrm{pH}, \mathrm{SEC}-\mathrm{Specific}$ Electrical Conductivity, Temperature). There are a few wells within the study area with SEC values above $1500 \mu \mathrm{S} / \mathrm{cm}$. This could be attributed to seawater intrusion as these wells are in close proximity to the sea (Fig. 3). The wells with SEC values lower than $1500 \mu \mathrm{S} / \mathrm{cm}$ are mainly under constant fresh water recharge from Nestos River (Gkiougkis, 2009; Mwila, 2009).

Evaluation and assessment of the qualitative characteristics of the samples of the study area aquifer from the selected wells occurred between 3/7/2009 and 8/7/2009. Chemical analyses took place at the Laboratory of Engineering Geology of Civil Engineering Department of Democritus University of Thrace. The chemical analyses were for the determination of certain chemical parameters such as $\mathrm{Ca}^{2+}, \mathrm{Mg}^{2+}, \mathrm{Na}^{+}, \mathrm{K}^{+}, \mathrm{HCO}_{3}{ }^{-}, \mathrm{Cl}^{-}, \mathrm{SO}_{4}{ }^{2-}, \mathrm{NO}_{3}{ }^{-}, \mathrm{NO}_{2}, \mathrm{NH}_{4}, \mathrm{PO}_{4}{ }^{3-}, \mathrm{SiO}_{2}, \mathrm{Fe}^{2+}, \mathrm{Mn}^{2+}$, alkalinity $\mathrm{M}$ and total hardness.

The chemical analysis results show that most of the wells contain low chloride $\left(\mathrm{Cl}^{-}\right)$with the exception of only $30 \%$ of the total wells studied which contain chloride with concentrations close to or above average. The average chloride concentration $216.64 \mathrm{mg} / \mathrm{L}$ in the wells from the study area is well below the limit of $250 \mathrm{mg} / \mathrm{L}\left(\mathrm{Cl}^{-}\right.$concentration range: $\left.15.60-1320.18 \mathrm{mg} / \mathrm{L}\right)$. Similarly, the nitrate $\left(\mathrm{NO}_{3}{ }^{-}\right)$concentrations in these wells show values below the maximum allowable standard for drinking water which is $44 \mathrm{mg} / \mathrm{L}$, with the exception of a few that show values which are close to the standard or way above the standard $\left(\mathrm{NO}_{3}{ }^{-}\right.$concentration range: $\left.0.00-60.00 \mathrm{mg} / \mathrm{L}\right)$. Plotting and contouring of these results show the spatial distribution of the high and low values and gives insight on the possible sources of contaminations. Figure 4 shows high chloride ions concentrations in the coastal region to the east of the study area. Comparing the map for SEC (Fig. 3) to the map of chloride ion distribution (Fig. 4) it is observed that in both maps high values are observed in wells located in the coastal region to the east of the study area. The high SEC and chloride ion concentration in this region could be attributed to seawater intrusion whereas the low values to the west of the study area are as a result of continuous fresh water recharge from Nestos River. There is little or no evidence of any anthropogenic influence in the concentration levels and their distribution. Nitrate on the other hand show an even distribution across the whole study area with high values found to the northwest, south and southeastern parts of the area. This distribution pattern could be attributed to the fact that the area is under heavy agricultural activities where use of fertilizer is common, and hence the high values observed (Gkiougkis, 2009; Mwila, 2009).

The results of the calculated SAR (Sodium Absorption Ratio) values show that over $90 \%$ of the wells under investigation contain suitable water for irrigation as the SAR values are well below the critical value 10 (Fig. 5). The increase in the $\mathrm{Na}^{+}$ion concentration is an indicator of fresh water mix- 


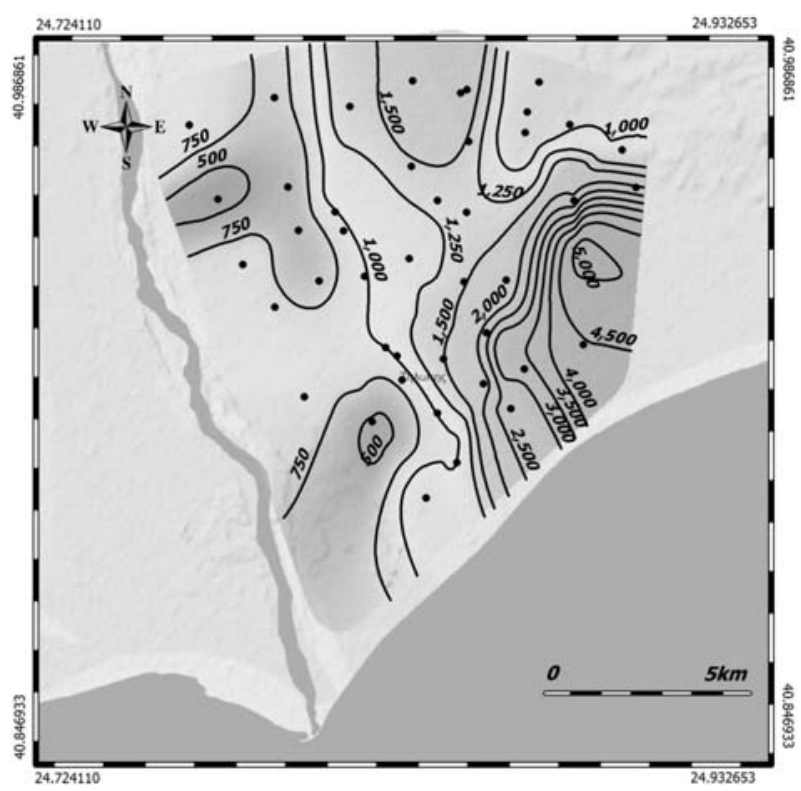

Fig. 3: Distribution of SEC values ( $\mu \mathrm{S} / \mathrm{cm})$ (Gkiougkis, 2009; Mwila, 2009).

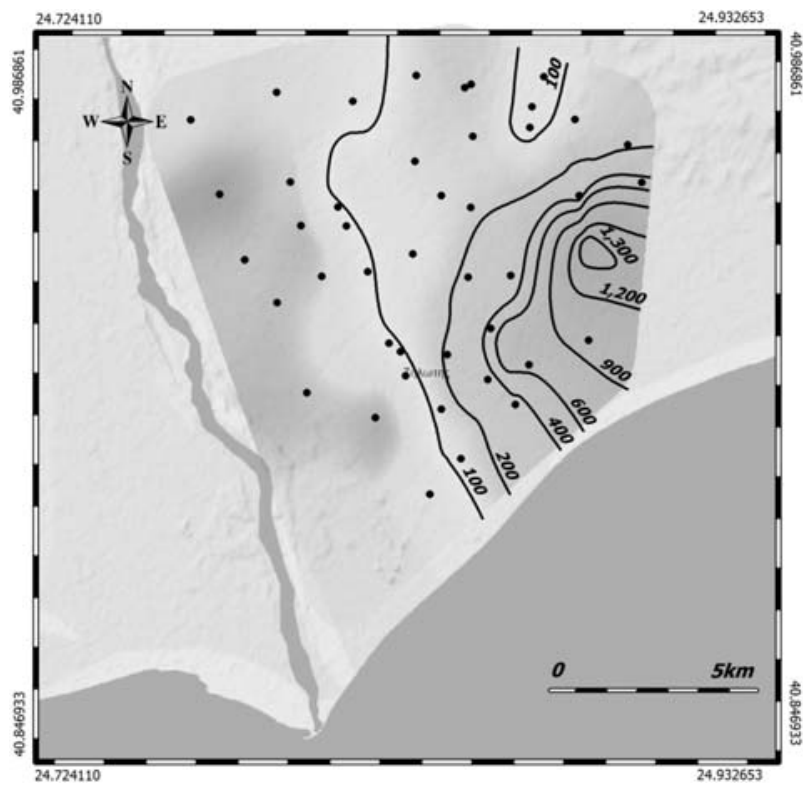

Fig. 4: Distribution of chloride ions (mg/L) of the groundwater samples of the study area (Gkiougkis, 2009; Mwila, 2009).

ing with saline water from the sea intruding the groundwater aquifer due to over pumping of groundwater for irrigation. However, this may also be as a result of evapotranspiration and/or calcite precipitation due to the presence of bicarbonates which effectively increase the $\mathrm{Na}^{+}$ions and tend to reduce the $\mathrm{Ca}^{2+}$ ion concentration in the groundwater thereby increasing the value of SAR and other 


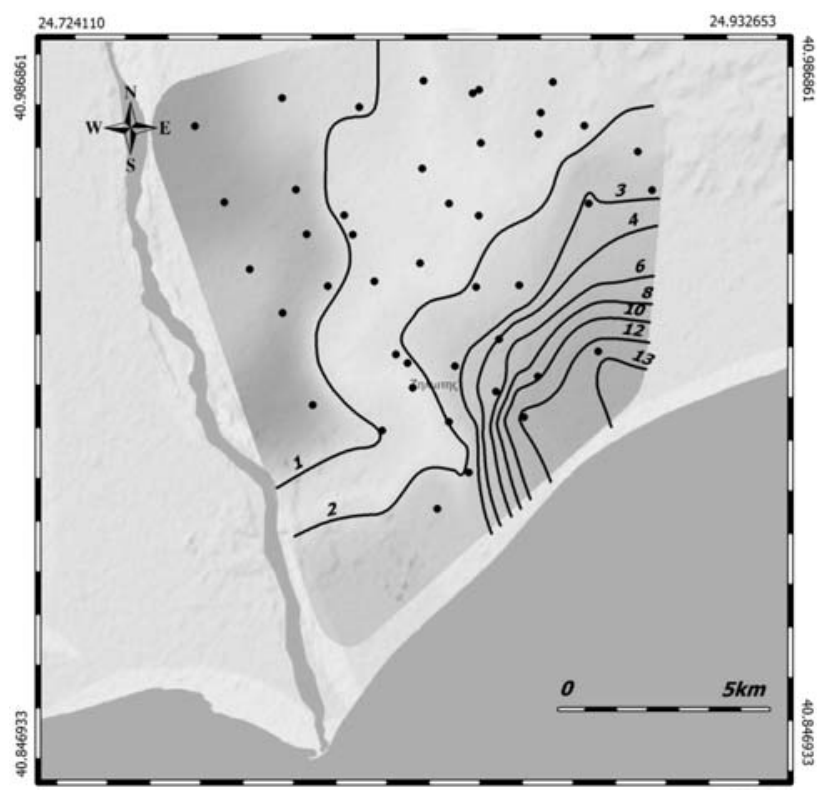

Fig. 5: Distribution of SAR values (Gkiougkis, 2009; Mwila, 2009).

toxic elements, particularly boron and chloride. The wells with higher to relatively high values of SAR are located to the east of the study area. Wells from the same location also contain relatively high amounts of chloride ion concentrations; have high values of specific electrical conductivity and $\mathrm{pH}$ values. All values of these parameters mentioned here affirm the argument of possible seawater intrusion into the groundwater aquifer in the eastern delta of Nestos River (Gkiougkis, 2009; Mwila, 2009).

The research showed generally relatively low percentages for the $\% \mathrm{Na}$ (Exchangeable Sodium Percentage - E.sp or $\mathrm{Na} \%$ ) in the groundwater samples. According to the qualitative classification of irrigation water after Wilkox 1955, it can be noted that most of the wells contain low levels of \% Na and can be classified having groundwater of either excellent to good quality with a few wells having acceptable groundwater quality for irrigation. There is only about $10 \%$ of the total number of wells under investigation with questionable groundwater quality (high \% Na values observed: 59.8977.92). Most wells with good groundwater quality for irrigation are located near the River Nestos and hence are under constant freshwater recharge. Further east to the coastal region of the study area the groundwater quality is compromised as a result of saline water from the sea mixing with freshwater in the aquifer due to seawater intrusion (Gkiougkis, 2009; Mwila, 2009).

Results of calculated Revelle Coefficient values for the groundwater samples revealed that most of the wells contain relatively low chloride ion concentrations as indicated by the low Revelle coefficient values. Few wells nonetheless show Revelle Coefficient values greater than 1.0 (Fig. 6). Making reference to the groundwater contamination limits from those suggested by Kallergis (2000), it suffices to state that all of the few wells which show values that indicate groundwater contamination could be classified as belonging to the categories ranging between groundwater with low level of contamination to groundwater with medium level of contamination. The wells with Revelle coefficient results greater than 1.0 (Revelle values: 1.48-9.45) are located to the east of the study area. 


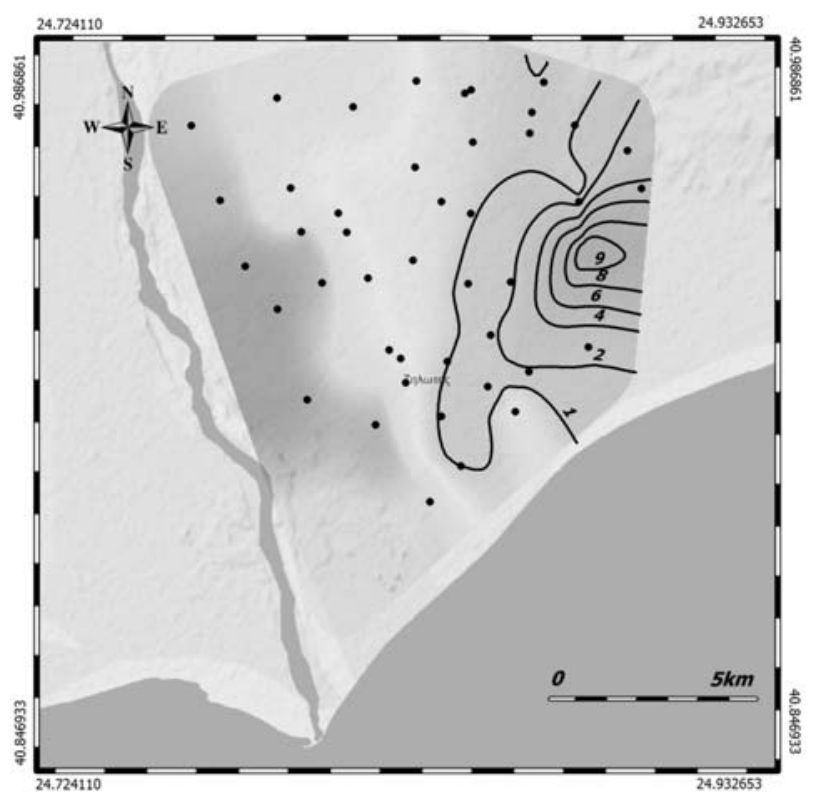

Fig. 6: Distribution of Revelle Coefficient values for the groundwater samples (Gkiougkis, 2009; Mwila, 2009).

This part of the study area has high chloride ion concentration and high values of electrical conductivity. The wells are close to the coast and as a result are susceptible to seawater ingress due to over abstraction of groundwater from the phreatic aquifer for irrigation purposes (Gkiougkis, 2009; Mwila, 2009).

\section{Conclusions - managerial proposals}

The problem of the groundwater salinisation at the study area appears to become serious, showing rapid deterioration in recent years. This finding makes the preparation of detailed studies on the region necessary, immediate and urgent to find efficient and certain solutions, for the region. Apart from proper groundwater artificial recharge applications at the study area, proposed by previous studies (Pliakas et al., 2001; Sakkas et al., 1998), the next step of enriching substantially the detailed elaboration of the seawater problem in the study area should focus on aspects related to (Pliakas, et al., 2007):

- conceptual model details (local geological details, hydrogeological boundaries),

- the hydraulic relationship between surface waters and groundwaters,

- the role of the Nestos River in the aquifer salinization process,

- hydrochemical modeling combined with proper additional field tests and hydrochemical types mapping,

- groundwater flow modeling of the studied aquifer system.

It is recommended that the environmental problem of seawater intrusion regime of the area should be assessed by the local authorities (relevant municipalities or prefecture) in the form of managerial reports which could include the following (Pliakas, et al., 2007): 
- study of providing freshwater sources and design of proper groundwater artificial recharge facilities with continuous evaluation of their effectiveness ,

- development of appropriate pumping scheme based on scientific evidence for the preservation of the entire piezometric surface of the area of investigation above sea level and organization of a series of educational seminars to the farmers of the area, in order to obtain appropriate knowledge for the pumping schemes which they should apply,

- construction of canals which will provide the migration of saline water towards preferred and certain parts of the study area,

- provision of specific measures for the problem of abandoned groundwater wells which may provide pathways for migration of saline water through different aquifer layers,

- thorough examination of the environmental impact assessment of each groundwater well which is about to be installed and inspection of the well drillers of the area and examination or evaluation of their scientific skills,

- development of a water authority, as demanded by Directive 2000/60/EC, to ensure the protection of the quality status of the groundwaters of the area.

The problem of seawater intrusion in Greece is a matter not only of insufficient or lack of groundwater resources management but also of poor legislation enforcement (Kallioras et al. 2004). The area of investigation is a typical example of lack of scientific groundwater resources management of coastal aquifers, which has resulted in the aggressive intrusion of seawater wedge at the mainland freshwater aquifer. The continuous over-pumping conditions and the overexploitation of the aquifer resources enhance the qualitative degradation of the aquifer and pose threats for a variety of factors of the area such as environmental, social, economic and agricultural development.

\section{Acknowledgments}

The contribution of Prof. Dr. Christoph Schüth is acknowledged, for the supervision of Mr. Mwila's Master Thesis for the fulfilment of the Master of Science degree in Tropical Hydrogeology, Engineering Geology and Environmental Management at the Institute of Applied Geosciences of the Technical University of Darmstadt.

\section{References}

Daskalopoulos, D., 2007. Hydrogeological study of an aquifer system at the eastern delta of Nestos River. Master Thesis, Postgraduate Course: Hydraulic Engineering, Department of Civil Engineering, Democritus University of Thrace, Xanthi, (in Greek).

Gaaloul, N., Pliakas, F., Kallioras, A., and Marinos, P., 2008. Seawater intrusion in Mediterranean porous coastal aquifers. Cases from Tunisia and Greece. Proceedings of the $8^{\text {th }}$ International Hydrogeological Congress of Greece and the $3^{\text {rd }}$ Middle and East Mediterranean Workshop on Fissured Rocks Hydrology, 8-10/10/2008, Athens, pp. 281-290.

Gkiougkis, I., 2009. Investigation of seawater intrusion into coastal aquifers in deltaic environment. The case of Nestos River Delta. PhD Thesis, Department of Civil Engineering, Democritus University of Thrace, Xanthi, (in progress), (in Greek).

Kallergis, G., 2000. Applied - Environmental Hydrogeology. Volume B, published TCG, Athens, $345 \mathrm{p}$ (in Greek).

Kallioras, A., Pliakas, F., and Diamantis, I., 2006. Conceptual model of a coastal aquifer system in northern Greece and assessment of saline vulnerability due to seawater intrusion conditions. Environmen- 
tal Geology, Springer, Vol. 51, n. 3, pp. 349-361.

Kallioras, A., Pliakas, F., Diamantis, I., 2004. The harmonization of national law with the Directive 2000/60 EC for the protection and management of waters. Environment and Law, Nomiki, Bibliothiki 4:480-488 (in Greek).

Mwila G., (2009). Groundwater quality degradation due to seawater intrusion conditions in a coastal unconfined aquifer in Northern Greece. Master Thesis, Technical University of Darmstadt, Institute of Applied Geosciences, Tropical Hydrogeology, Engineering Geology and Environmental Management (MSc-Trophee), Darmstadt, Germany, 60 p.

Pliakas, F., Diamantis, I., and Petalas, C., 2001. Saline water intrusion and groundwater artificial recharge in east delta of Nestos River. Proceedings of the $7^{\text {th }}$ International Conference on Environmental Science and Technology, University of the Aegean, Dept. of Environmental Studies, and Global Nest, Ermoupolis, Syros, Greece, 3-6/9/2001, Vol. 2, pp. 719-726.

Pliakas, F., Mouzaliotis, A., Kallioras, A., and Diamantis, I., 2007. Hydrogeological assessment of the salinization problem of Xilagani - Imeros aquifer system in SW plain area of Rhodope Prefecture, Greece. Proceedings of the $11^{\text {th }}$ International Conference of the Geological Society of Greece, Athens, Greece, 24-26/5/2007, Vol. 2, pp. 536-547.

Sakkas, I., I. Diamantis and F. Pliakas, et al., 1998. Groundwater artificial recharge study of Xanthi Rhodopi aquifers (in Thrace, Greece). Greek Ministry of Agriculture Research Project, Final Report. Sections of Geotechnical Engineering and Hydraulics of the Civil Engineering Department of Democritus University of Thrace, Xanthi, Greece, (in Greek).

Wilcox, L.V., 1955. Classification and use of irrigation waters, U.S. Dept. Agric. Circ. 969. 